\title{
A Real-World Evaluation of Clinical Outcomes of Biologicals and Bronchial Thermoplasty for Severe Refractory Asthma (BIOTERM)
}

\author{
Francesco Menzella $\mathbb{D}^{1}$ \\ Matteo Fontana' \\ Carla Galeone' \\ Maria D'Amato \\ Giorgio Walter Canonica ${ }^{3}$ \\ Giulia Ghidoni' \\ Silvia Capobelli' \\ Chiara Scelfo (D) ${ }^{\prime}$ \\ Anna Simonazzi ${ }^{\prime}$ \\ Chiara Catellani' \\ Patrizia Ruggiero' \\ Nicola Facciolongo' \\ 'Pulmonology Unit, Arcispedale Santa \\ Maria Nuova, Azienda USL di Reggio \\ Emilia- IRCCS, Reggio Emilia, 42I23, Italy; \\ ${ }^{2}$ Department of Pulmonology, AO "Dei \\ Colli" Federico II University, Naples, \\ 80I3I, Italy; ${ }^{3}$ Personalized Medicine, \\ Asthma and Allergy - Humanitas Clinical \\ and Research Center, IRCCS - Rozzano, \\ Milan, Italy
}

Correspondence: Francesco Menzella Pulmonology Unit, Arcispedale Santa Maria Nuova, Azienda USL di Reggio Emilia- IRCCS, Reggio Emilia, 42I23, Italy Email francesco.menzella@ausl.re.it
Background: The important progress made on asthma phenotyping encouraged the development of new therapeutic strategies, such as monoclonal antibodies (mAbs) and bronchial thermoplasty (BT). The aim of this study is to compare patients diagnosed with severe refractory asthma (SRA) who are currently being treated with omalizumab, mepolizumab, benralizumab or BT and to evaluate the efficacy of these treatments over a 12-month observation period.

Methods: Overall, 199 consecutive patients with SRA were included. The cohort was selected referring to the eligibility criteria for all available biologics and BT.

Results: Among 32 patients treated with benralizumab, we found a $16.7 \%$ reduction in hospitalizations, a $66.6 \%$ reduction in exacerbations $(\mathrm{p}=0.0001)$ and the greater improvement in FEV1 $(+37.4 \%, \mathrm{p}<0.0001)$. Among omalizumab group (54 patients), there was a $85.7 \%(p=0.012)$ reduction in hospitalizations and a $88.8 \%(p<0.0001)$ reduction in exacerbations. In the mepolizumab group (83 patients), we found a $89.5 \%(\mathrm{p}=0.02)$ reduction in hospitalizations and a $92.1 \%(\mathrm{p}<0.0001)$ reduction in exacerbations. BT subgroup (30 patients) showed a 93.7\% $(\mathrm{p}=0.001)$ reduction in hospitalizations and a $73.5 \%(\mathrm{p}<0.0001)$ reduction in exacerbations. The best results in terms of OCS sparing effect were obtained by BT $(-76 \%, \mathrm{p}<0.0001)$ and mepolizumab $(-90.2 \%, \mathrm{p}=0.002)$. Omalizumab showed the highest percentage of super responder patients.

Conclusion: To our knowledge, this is the first study to compare all marketed mAbs with BT, ending in more comprehensive and applicable results to clinical practice. All biologics, to varying degrees, reduced hospitalizations, exacerbations, and OCS use. The starting point for patients in the BT group was worse regarding hospitalizations, exacerbations and OCS, but despite this, even this non-pharmacological option obtained positive results, comparable to biologics.

Keywords: severe asthma, biologics, bronchial thermoplasty, oral corticosteroids, exacerbations

\section{Introduction}

Asthma is a very heterogeneous disease, varying from forms with mild bronchial obstruction to other serious ones, up to severe refractory asthma (SRA). Dividing the heterogeneity of asthma into phenotypes is complex due to the scarcity of specific and validated biomarkers. Most of the phenotyping process is mainly based on cross-sectional, retrospective, epidemiological data, symptom pattern, atopic state, bronchial obstruction pattern and others. ${ }^{1}$ These clinical phenotypes often overlap and can sometimes change over time. 
Recent clinical and immunological phenotypic classifications of asthma encouraged the development of new therapeutic strategies, such as the discovery of monoclonal antibodies (mAbs) targeted to $\mathrm{IgE}$ (anti-IgE/omalizumab), or anti interleukin-5 (IL-5), specific for the Type 2 (T2)high eosinophilic phenotype. ${ }^{2}$ Anti-IgE therapy with omalizumab was the first therapeutic option for the treatment of severe allergic asthma.

AntilL-5 biologics such as mepolizumab and reslizumab and anti IL-5 receptor alpha subunit such as benralizumab have recently been approved as add-on treatments in patients with severe eosinophilic refractory asthma. To date, other drugs are being developed aimed at treating the T2-high phenotype. Despite these great advances, knowledge is still limited regarding other potential phenotypes and endotypes of severe asthma, such as non-eosinophilic asthma and the T2-low phenotype (neutrophilic and paucigranulocytic). ${ }^{3}$

To date, bronchial thermoplasty (BT) is mainly addressed as a therapy for the T2-low asthma endotype. It is an endoscopic procedure approved by the US Food and Drug Administration (FDA) in 2010 for the treatment of severe asthma. ${ }^{4} \mathrm{BT}$ is a non-drug option for the treatment of moderate-to-severe refractory asthma based on the release of controlled heat at $65^{\circ} \mathrm{C}$ aimed at modifying the structure of the bronchial wall by reducing the amount of smooth muscle. The device used for BT is a catheter called Alair System (Boston Scientific, Natick, MA, USA). ${ }^{5}$

There are currently no comparative studies between the different biologics and BT in a real-world context. Furthermore, BT is still considered a procedure to be reserved almost exclusively for patients not eligible for biologics and probably less effective than mAbs. For these reasons, it is important to obtain data that allow comparison of pharmacological and non-pharmacological options in the different phenotypes of patients with severe asthma.

In light of the different therapeutic options available for the treatment of SRA, the rationale of the present study is to compare patients diagnosed with severe asthma who are currently being treated with omalizumab, mepolizumab, benralizumab and BT and to evaluate the efficacy of these treatments over a 12-month observation period.

\section{Methods}

\section{Ethical Approval}

This study was approved by the local ethics committee (Ethics Committee of the Vast Emilia North Area Azienda USL di Reggio Emilia- IRCCS, Reggio Emilia
15/11/2017), protocol number 2020/0013491 and Ethics Committee of University "Luigi Vanvitelli" - AORN "Ospedali dei Colli" protocol number 11652/2020. This protocol was performed according to the Good Clinical Practice (ICH Harmonized Tripartite Guidelines for Good Clinical Practice 1996; Directive 91/507. EEC, The Rules Governing Medical Produced in the European Community) and in compliance with Italian laws (D.L.vo n.211 of 24 June 2003; D.L. n.200 of 6 November 2007; MD of 21 December 2007).

\section{Study Population}

In this retrospective real-life study, patients enrolled were aged $>12$ years and suffered from SRA according to ERS/ ATS severe asthma guidelines 2019 and GINA 2020; they were referred to the Pulmonology Unit of AUSL of Reggio Emilia/IRCCS in Reggio Emilia, Italy and in Department of Pulmonology, Monaldi Hospital, Naples, Italy, since January 2019 to January 2020.

For each patient, we collected the following data: demographic data (age, sex, age of onset of asthma, history of smoking, presence of allergies, comorbidities); clinical data (lung function, exacerbations, emergency department (ED) visits and hospitalizations); patientreported outcomes (asthma quality of life questionnaire - AQLQ, asthma control questionnaire - ACQ); serum biomarkers (blood eosinophil count and total serum IgE); drug therapies for asthma (inhaled corticosteroids/longacting $\beta$-adrenoceptor agonists (ICS/LABA), long-acting muscarinic antagonists (LAMA), leukotriene receptor antagonists (LTRA), theophylline, oral corticosteroids (OCS), biologics (omalizumab, mepolizumab and benralizumab) and BT.

The cohort was selected referring to the eligibility criteria for every biologic. Specifically, omalizumab criteria: age $\geq 6$ and $\leq 75$ years; total serum levels of $\operatorname{IgE} 76 \leq$ $\operatorname{IgE} \leq 1500 \mathrm{IU} / \mathrm{L} ; \geq 1$ exacerbations of asthma that required OCS, ED visits or hospitalizations in the previous 12 months; positive result on skin prick test or specific serum $\operatorname{IgE}$ for a perennial allergen; forced expiratory volume $\left(\mathrm{FEV}_{1}\right)<80 \%$ pre-bronchodilator (pre-BD). Mepolizumab criteria: age $\geq 18$ years; elevated peripheral blood eosinophil count ( $\geq 150$ cells $/ \mu \mathrm{L}$ a screening or $\geq 300$ cells/ $\mu \mathrm{L}$ within 12 months prior to enrollment); $\geq 2$ exacerbations of asthma requiring OCS, ED visits or hospitalizations in the previous 12 months. Benralizumab criteria: age $\geq 18 \leq 75$ years; high peripheral blood eosinophil count ( $\geq 300$ cells $/ \mu \mathrm{L}$ in the previous 12 months before 
enrollment); $\geq 2$ exacerbations of asthma requiring OCS, ED visits or hospitalizations within the previous 12 months. BT criteria: age $\geq 18$ years; $\geq 2$ exacerbations of asthma requiring OCS, ED visits or hospitalizations during the 12 months prior to study initiation; $\mathrm{FEV}_{1}>60 \%$ preBD.

In detail, omalizumab was considered the biological treatment of choice for patients with severe noneosinophilic allergic asthma, high blood $\operatorname{IgE}$ levels and at least one sensitization to a perennial allergen. Conversely, an anti-IL-5 biological agent was selected for patients with severe eosinophilic non-allergic asthma. Due to the lack of head-to-head comparative studies, currently there are no specific recommendations in order to choose among all available biologics targeting the IL-5 pathway. Regarding this, a matching-adjusted indirect comparison indicated that benralizumab and mepolizumab have similar efficacy profiles. $^{8}$ Other indirect comparison studies between these two biologics showed conflicting data. For these reasons, there are no clear indications in choosing one of these two options at the moment. 9,10

Patients undergoing BT were the ones who were ineligible for biologics, patients who had not responded to a biologic, or those who were unwilling to undergo biological therapy for life.

Regarding therapeutic switches, the most frequent reasons that led to the interruption of a biological therapy in order to start another one were the lack of symptom control or the patient's request. No switches were caused by adverse events. We performed a direct switch between two treatments without a wash-out period.

Reslizumab and dupilumab were not considered because they were not available on market in Italy at the time of the study enrollment.

The exclusion criteria were:

- Absence of signed informed consent;

- Absence of a consent on privacy, data collection and analysis in aggregate form;

- Absence of a diagnosis of severe asthma, made according to the definition of the document ERS/ ATS 2014;

There were no other exclusion criteria, in order to allow a real-life view of the characteristics of these patients with severe asthma. All patients undergoing treatment for 1 year were included in the study, regardless of response to therapy.

\section{Outcomes}

Primary Endpoint

- Measurement of the frequency of moderate-to-severe exacerbations in the $12 \pm 2$ months from the start of treatment. Moderate exacerbations were defined as deterioration of the patient's symptoms or lung function beyond normal daily changes requiring drug modification. Severe exacerbations are defined on the basis of the need for urgent interventions, such as prescribing systemic steroids (oral or injected) or increasing the dose of maintenance steroids for at least 3 days, emergency room visits or hospitalization due to worsening of symptoms.

\section{Secondary Endpoints}

- Proportion of super-responders (complete cessation of exacerbations, complete OCS withdrawal and little or no symptoms (ACT > 20 and ACQ $<1.5$ ).

- Dosage of standard care drugs (ICS/LABA/LAMA/ LTRA).

- Daily dosage of OCS.

- Improvement of the quality of life (QoL) in terms of scores in AQLQ, ACT, ACQ questionnaires.

\section{Statistical Analysis}

Statistical analysis was performed with Prism 8.0 statistical software package (GraphPad Software, Inc., La Jolla, CA, USA). Demographic and clinical characteristics were analyzed and compared between groups at baseline and after the follow up, measuring also the variations of clinical features and outcomes within each group.

The paired $t$ test and Wilcoxon test were used to compare two groups of continuous variables, while Kruskal-Wallis test, Brown-Forsythe test, and Welch ANOVA test were used to compare 4 groups of continuous variables. Chi-square test and Fisher's exact test were used for the comparison between categorical variables. A $p$ value of less than 0.05 was considered statistically significant.

\section{Results}

Overall, 199 consecutive patients with SRA were included. Among these, $60 \%$ were female and the mean age was 56.5 \pm 12.9 years, range 18-81 (Table 1). Of 199 patients, 65 (33\%) were ex-smokers and pre-BD FEV1 was $68 \pm 18$ of predicted. Regarding asthma concomitant medications, daily mean dose of ICS was $1045.2 \pm 455.6 \mathrm{mcg}, 140(50 \%)$ patients took LAMA, 94 (34\%) patients took LTRA and 
$97(49 \%)$ of our study population received maintenance OCS at the time of enrollment. Fifty-four out of 199 patients (27\%) took omalizumab, 83 (42\%) took mepolizumab, 32 (16\%) took benralizumab and $30(15 \%)$ underwent BT.

The mean age of SRA onset was $33.8 \pm 14.9$ years old, $65 \%$ of the study population was atopic, $38 \%$ was sensitive to more than one aero-allergen and $65 \%$ was eosinophilic (blood eosinophil count $($ BEC) $>300$ cells $/ m L)$. An overlap among atopic and eosinophilic endotypes was present in $56(28 \%)$ of patients.

Among 32 patients (16\%) treated with benralizumab (Table 2), BEC was $787.3 \pm 905.2$ cells $/ \mathrm{mL}$ at baseline and $0.0 \pm 0.0$ post-treatment $(\mathrm{p}<0.0001)$, total $\operatorname{IgE}$ mean value was $353.7 \pm 504.7 \mathrm{kU} / \mathrm{L}$ at baseline and $271.8 \pm 428.2$ post-treatment, Asthma Control Test (ACT) score increased by 4.2 points at the end of the treatment $(\mathrm{EOT})(\mathrm{p}<0.0001)$, mean hospitalizations number per year was $0.4 \pm 1.2$ at baseline and $0.3 \pm$ $1.1(-16.7 \%)$ at EOT, mean exacerbations number per year was $2.5 \pm 2.6$ at baseline and $0.8 \pm 2$ $(-66.6 \%)(\mathrm{p}=0.0001)$ at EOT, $\mathrm{FEV}_{1}(\mathrm{~L})$ was $1.8 \pm$ 0.8 before benralizumab and $2.4 \pm 1(+37.4 \%)$ at the EOT $(\mathrm{p}<0.0001)$. Regarding OCS, mean prednisone dose at baseline was $4.4 \pm 7.6 \mathrm{mg}$ at baseline and $3.4 \pm$ $7.5 \mathrm{mg}(-23.6 \%)$ at the EOT $(\mathrm{p}=0.06)$ (Table 2 and Figure 1).

Among omalizumab group (54 out of 199 patients, $27 \%$ ), BEC was $351.4 \pm 362.7$ cells $/ \mathrm{mL}$ at baseline and $327.3 \pm 292.4$ post-treatment, total IgE mean value was $577.4 \pm 886.1 \mathrm{kU} / \mathrm{L}$ at baseline and $578 \pm 621$ posttreatment, ACT score increased by 7.2 points at the end of the treatment $(\mathrm{p}<0.0001)$, mean hospitalization number per year was $0.3 \pm 0.6$ at baseline and $0.04 \pm$ $0.2(-85.7 \%)(\mathrm{p}=0.012)$ at EOT, mean exacerbation number per year was $4.1 \pm 2.1$ at baseline and $0.5 \pm 0.6$ $(-88.8 \%)(\mathrm{p}<0.0001), \mathrm{FEV}_{1}(\mathrm{~L})$ was $1.9 \pm 0.8$ before omalizumab and $2.4 \pm 1(+4.7 \%)$ at the end of treatment period (Table 2). Regarding OCS, mean prednisone dose at baseline was $2.4 \pm 4.6 \mathrm{mg}$ and $0.6 \pm$ $1.7 \mathrm{mg}(-75.7 \%)$ at $\operatorname{EOT}(\mathrm{p}=0.01)$ (Table 3 and Figure 1).

In the evaluation of 83 patients treated with mepolizumab (42\%), BEC was $623.9 \pm 591.7$ cells $/ \mathrm{mL}$ at baseline and $139.2 \pm 389.9$ post-treatment $(\mathrm{p}<0.0001)$, total IgE mean value was $317.9 \pm 507.7 \mathrm{kU} / \mathrm{L}$ at baseline and $229.2 \pm 504.8$ post-treatment $(\mathrm{p}=0.03)$, ACT score increased by 7.4 points at the end of the treatment ( $p$ $<0.0001)$, mean hospitalization number per year was $0.3 \pm 0.9$ at baseline and $0.04 \pm 0.2(-89.5 \%)(\mathrm{p}=0.02)$ at EOT, mean exacerbation number per year was $5 \pm 2.3$ at baseline and $0.4 \pm 0.9(-92.1 \%)(p<0.0001)$ at EOT, $\mathrm{FEV}_{1}(\mathrm{~L})$ was $1.96 \pm 0.85$ before mepolizumab and 2.21 $\pm 0.78(+11.9 \%)$ at the EOT period $(\mathrm{p}=0.01)$. Regarding OCS, mean prednisone dose at baseline was $11 \pm 26.9 \mathrm{mg}$ and $1.1 \pm 4.6 \mathrm{mg}(-90.2 \%)$ at $\operatorname{EOT~}(\mathrm{p}=$ 0.002) (Table 4).

Within the subgroup of 30 patients who underwent BT $(15 \%)$, BEC was $348.3 \pm 537.5$ cells $/ \mathrm{mL}$ at baseline and $392 \pm 284.3$ post-treatment, total $\mathrm{IgE}$ mean value was $165.9 \pm 288.8 \mathrm{kU} / \mathrm{L}$ at baseline and $166.5 \pm 192.9$ post-treatment $(\mathrm{p}=0.03)$, ACT score increased by 5.9 points at EOT $(\mathrm{p}<0.0001)$, mean hospitalization number per year was $1.1 \pm 1.6$ at baseline and $0.07 \pm 0.2$ ($93.7 \%)(\mathrm{p}=0.001)$ at EOT, mean exacerbation number per year was $5.6 \pm 3.4$ at baseline and $1.5 \pm 1(-73.5 \%)$ $(\mathrm{p}<0.0001)$ at EOT, $\mathrm{FEV}_{1}(\mathrm{~L})$ was $1.9 \pm 0.8$ before BT and $2.2 \pm 1(+5.7 \%)$ at EOT period (Figure 1). Regarding OCS, mean prednisone dose at baseline was $14.7 \pm 10.2 \mathrm{mg}$ and $3.5 \pm 4.9(-76 \%)$ after BT $(\mathrm{p}<$ 0.0001 ) (Table 5).

The proportion of super responders was 47\% (15) in benralizumab group, 58\% (48) in mepolizumab group, $61 \%$ (33) in omalizumab group and $10 \%$ (3) in BT group ( $\mathrm{p}<0.0001)$. In detail, the proportion of patients who weaned off from OCS was $72 \%$ (23) in benralizumab group, 69\% (57) in mepolizumab group, 89\% (48) in omalizumab group and $53 \%$ (16) in BT group $(p=0.013)$. The proportion of patients who achieved good symptom control was 59\% (19) in benralizumab group, 85\% (71) in mepolizumab group, 85\% (46) in omalizumab group and 33\% (10) in BT group $(\mathrm{p}<$ $0.0001)$. Finally, the proportion of patients with partial response and who may require a treatment switch was $16 \%$ (5) in benralizumab group, $10 \%$ (8) in mepolizumab group, $5.5 \%$ (3) in omalizumab group and 10\% (3) in BT group $(\mathrm{p}=0.32)$.

The improvement in ACQ score was statistically significant for all treatment options while AQLQ improved significantly for all treatments except benralizumab (Figure 2 and Supplementary Table). Altogether, few therapeutic switches occurred in the cohort of patients examined, with the highest number occurring 


\begin{tabular}{|c|c|c|c|c|c|c|c|c|c|c|c|c|c|c|c|c|c|c|c|c|c|c|}
\hline $\begin{array}{l}\frac{0}{J} \\
\frac{\partial}{J} \\
a\end{array}$ & $\S$ & $\stackrel{\substack{0 \\
0}}{0}$ & 茴 & ô. & $\stackrel{\div}{\circ}$ & $\begin{array}{l}\bar{\delta} \\
\text { ò } \\
\text { v }\end{array}$ & $\begin{array}{l}\text { 翣 } \\
0 \\
0\end{array}$ & $\frac{m}{o}$ & ర్రి & $\frac{\infty}{0}$ & స్ & ঃ̊ & ָ̃ & นึ่ & $\frac{m}{0}$ & $\S$ & $\stackrel{T}{0}$ & $\stackrel{\text { nم }}{\hat{~}}$ & 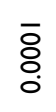 & $\begin{array}{l}\bar{\delta} \\
\text { o. } \\
\text { o }\end{array}$ & $\begin{array}{l}\overline{8} \\
\text { ọ } \\
\text { v }\end{array}$ & $\begin{array}{l}\bar{\delta} \\
\dot{0} \\
\dot{\mathrm{v}}\end{array}$ \\
\hline
\end{tabular}

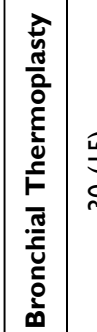

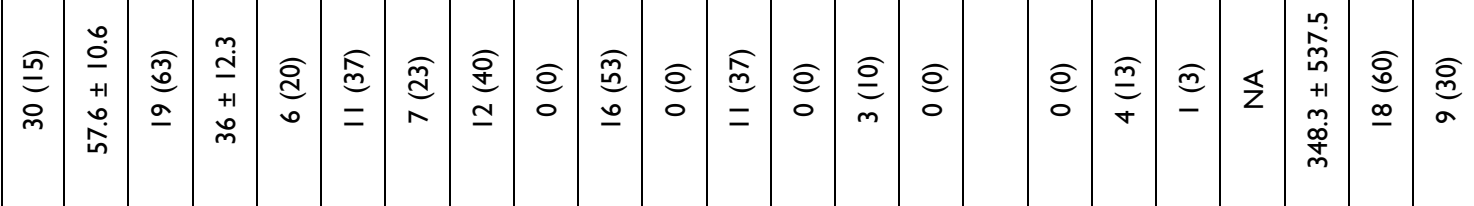

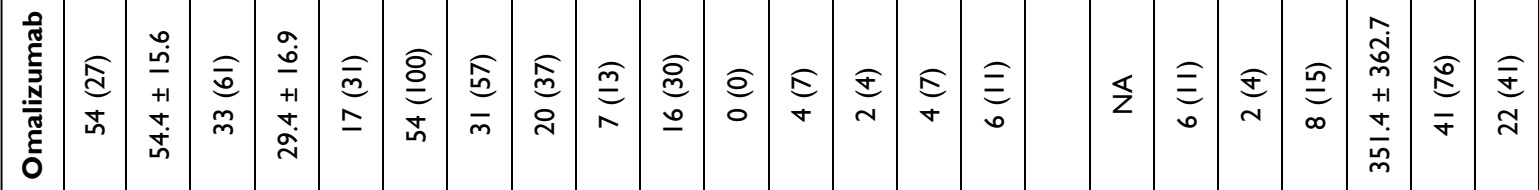

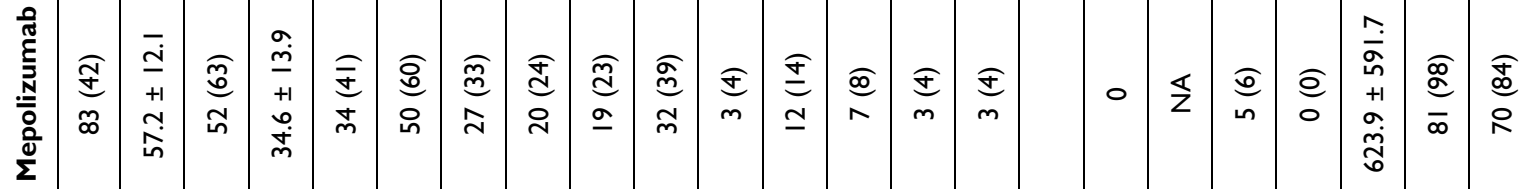

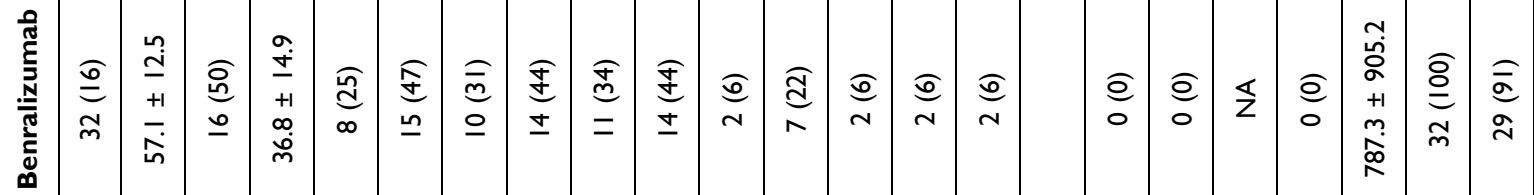

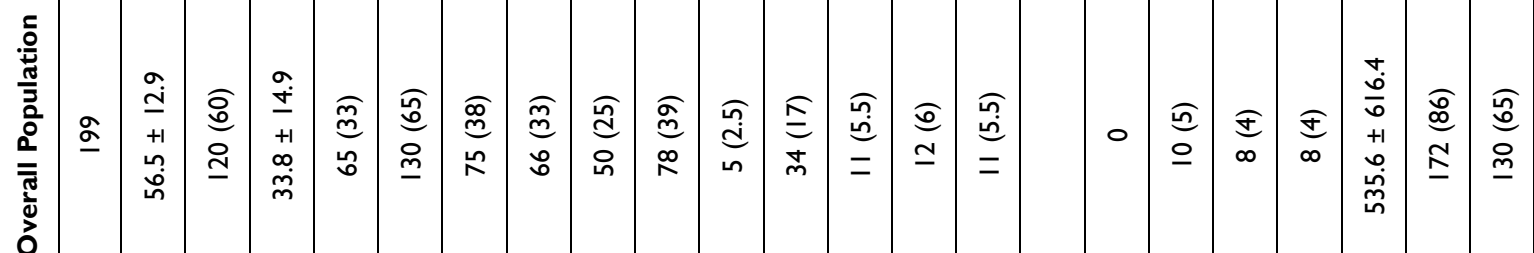

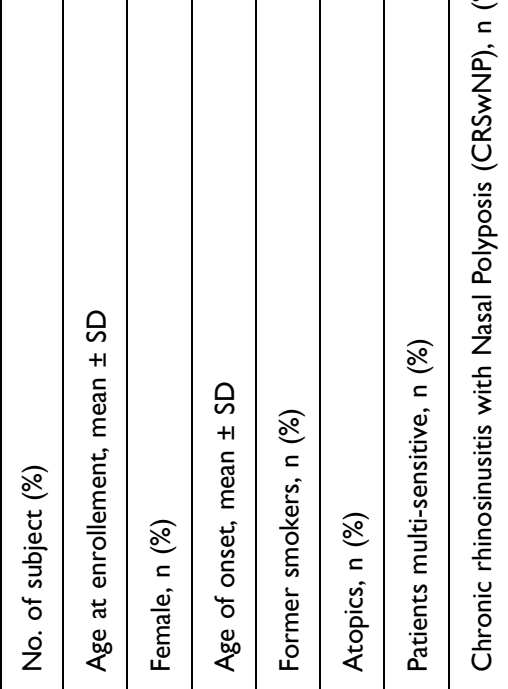




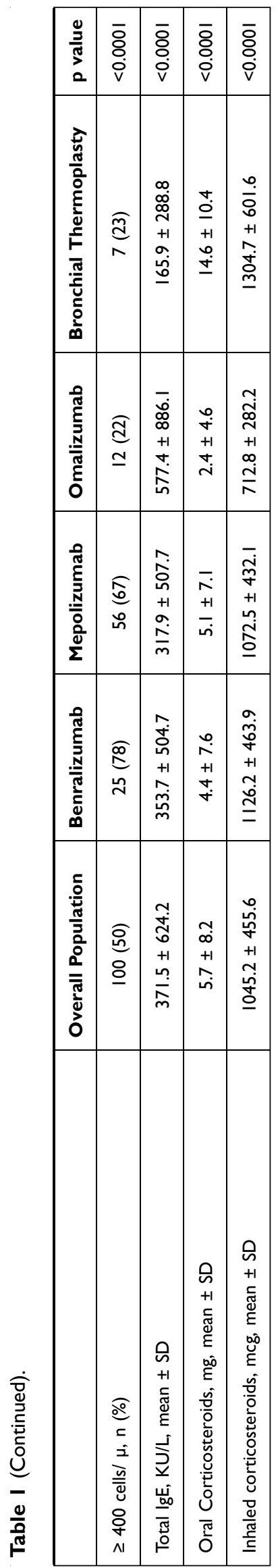

among subjects treated with omalizumab and then undergoing BT (8 patients, 27\%). Five patients (16\%) treated with mepolizumab then received benralizumab. Therapeutic switches between the other groups were infrequent. Regarding OCS use in this subgroup, there are no differences between the means of patients who received omalizumab before $\mathrm{BT}$ versus those who did BT alone (at baseline, respectively, $18.33 \mathrm{mg} /$ patient/day \pm 10.80 and $13.75 \pm 10.11$ with $p=0.38$ while after BT $5.83 \pm 5.63$ and $2.91 \pm 4.59$ with $\mathrm{p}=0.28$ ); as a difference, in both groups the variations are statistically significant, in patients who first received omalizumab the difference is $-12.5 \pm 10.25$ with $p=0.03$, while in patients who received BT alone it is $-10.84 \pm 9.25$ with $\mathrm{p}<0.0001$.

As for standard care drugs, a significant reduction was found only for LAMA, LTRA and theophylline in the mepolizumab group (Supplementary Table).

\section{Safety Profile}

No mild or severe side effects were observed throughout the treatment period.

\section{Discussion}

In literature there is only one real-world comparison study between $\mathrm{BT}$ and biologics, only including mepolizumab but not the other available agents. It was a single-center, observational cohort study on 91 patients, which showed that after 12 months there were no differences between treatment outcomes evaluating ACQ, reduction of exacerbation rate and OCS dose. ${ }^{11}$ Unlike this study, ours compare all marketed mAbs at the time of patient enrolment with BT, ending in more comprehensive and applicable results to clinical practice.

To our knowledge, this is the first study to compare not only different biologicals but also a non-drug treatment option such as BT in a real-life setting. This study presents comparative results from a large cohort of severe refractory severe asthma patients treated in two referral centers with all biologics available at the time of enrollment and with BT. There are currently no prospective head-to-head comparative studies from different biologics and $\mathrm{BT}$, so these data could be extremely useful for clinical practice and for making the difficult choice between different therapeutic options, especially in the case of phenotypic overlap. The increasing availability of different therapeutic approaches implies a careful selection of severe asthma patients, based on 
Table 2 Outcomes Variations in Benralizumab Group

\begin{tabular}{|c|c|c|c|}
\hline \multicolumn{4}{|c|}{ Benralizumab } \\
\hline & Pre & Post & p value \\
\hline Eos (cell/mcl), mean \pm SD & $787.3 \pm 905.2$ & $0.0 \pm 0.0$ & $<0.000$ I \\
\hline Eos (\%), mean $\pm S D$ & $9.2 \pm 5.3$ & $0.06 \pm 0.04$ & $<0.0001$ \\
\hline Neutr (cell/mcl), mean \pm SD & $4153 \pm 1171$ & $4212 \pm 1615$ & 0.86 \\
\hline Neutr (\%), mean \pm SD & $49.9 \pm 8.2$ & $52.2 \pm 14.5$ & 0.28 \\
\hline $\operatorname{lgE}$ tot $(\mathrm{kU} / \mathrm{L})$, mean $\pm \mathrm{SD}$ & $310 \pm 490.3$ & $271.8 \pm 428.2$ & 0.09 \\
\hline $\mathrm{ACT}$, mean $\pm \mathrm{SD}$ & $15.3 \pm 3.9$ & $17.8 \pm 4.6$ & 0.0009 \\
\hline $\mathrm{ACQ}$, mean $\pm \mathrm{SD}$ & $3.4 \pm 0.7$ & $1.1 \pm 1.4$ & $<0.0001$ \\
\hline AQLQ, mean \pm SD & $3.9 \pm 1.2$ & $4.4 \pm 1$ & 0.008 \\
\hline Hospitalizations in the last year, mean $\pm S D$ & $0.4 \pm 1.2$ & $0.3 \pm 1.1$ & 0.32 \\
\hline Exacerbations in the last year, mean $\pm S D$ & $2.5 \pm 2.6$ & $0.8 \pm 2$ & 0.0001 \\
\hline $\mathrm{FEV}_{\mathrm{I}}(\mathrm{L})$, mean $\pm \mathrm{SD}$ & $1.8 \pm 0.8$ & $2.4 \pm 1$ & $<0.0001$ \\
\hline $\mathrm{FEV}_{1}(\%)$, mean $\pm \mathrm{SD}$ & $60 \pm 19.8$ & $80.9 \pm 23.5$ & $<0.000$ I \\
\hline $\mathrm{FVC}(\mathrm{L})$, mean $\pm \mathrm{SD}$ & $2.8 \pm 0.9$ & $3.4 \pm 1.3$ & $<0.000$ I \\
\hline $\mathrm{FVC}(\%)$, mean $\pm \mathrm{SD}$ & $78.2 \pm 19.1$ & $93 \pm 21.7$ & 0.0003 \\
\hline $\mathrm{FEV}_{\mathrm{I}} / \mathrm{FVC}$, mean $\pm \mathrm{SD}$ & $63.9 \pm 10$ & $69.6 \pm 12.2$ & 0.04 \\
\hline ICS (mcg/die), mean \pm SD & $1126 \pm 464$ & $1095 \pm 488.4$ & 0.5 \\
\hline OCS (mg/die), mean $\pm S D$ & $4.4 \pm 7.7$ & $3.4 \pm 7.5$ & 0.06 \\
\hline LAMA, n (\%) & $26(8 I)$ & $23(72)$ & 0.56 \\
\hline LTRA, n (\%) & $16(50)$ & $14(44)$ & 0.8 \\
\hline Theophylline, n (\%) & $5(16)$ & $5(16)$ & $>0.99$ \\
\hline
\end{tabular}

clinical evaluation and identification of available biomarkers. The combination of these data allows to identify specific phenotypes and molecular targets that can guide the choice of the correct treatment option. As for biological drugs, the choice is supported by biomarkers. As for now, no real biomarker for BT is available, the choice of which usually takes place in case of patients who are not eligible for biologics or refractory to them. In our cohort, patients eligible to BT were selected based on lung function $\left(\mathrm{FEV}_{1}>60 \%\right)$, also in light of the inclusion criteria of the AIR1 study. ${ }^{12}$ Recent studies applied other eligibility criteria, such as $\mathrm{FEV}_{1}<50 \%$, ${ }^{13}$ but these data refer to a small population. The difficult choice between different therapeutic options, the lack of head-to-head data and above all the absence of predictive biomarkers sometimes lead to the need of carrying out therapeutic switches as often reported in literature and as shown in a previous study we published. ${ }^{14}$ Although the number of patients treated with single biologics and with BT differs not only in terms of characteristics but also in terms of sample size, the data obtained are extremely interesting and surprising for various aspects. In general, the effectiveness of biologics and BT is confirmed, but some unexpected data emerge by analyzing in detail every parameter examined.

The largest patient subgroup was the one treated with mepolizumab (83), which had a higher mean OCS dose at baseline than other biologics $(10.8 \mathrm{mg})$, likely indicative of greater asthma severity. At the end of the 

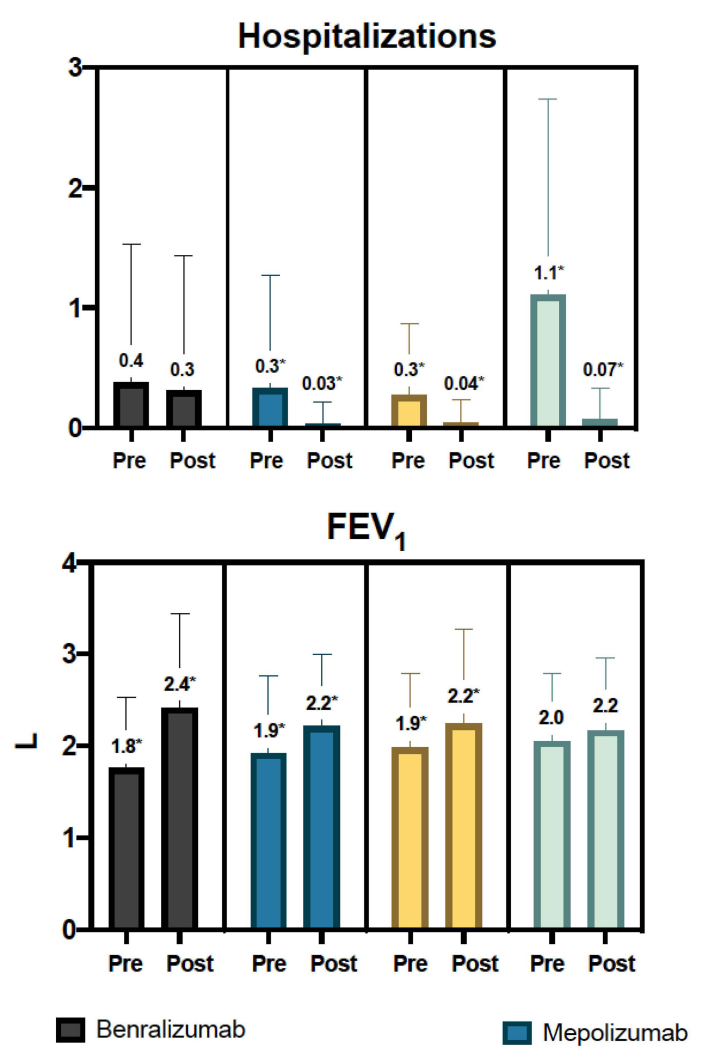
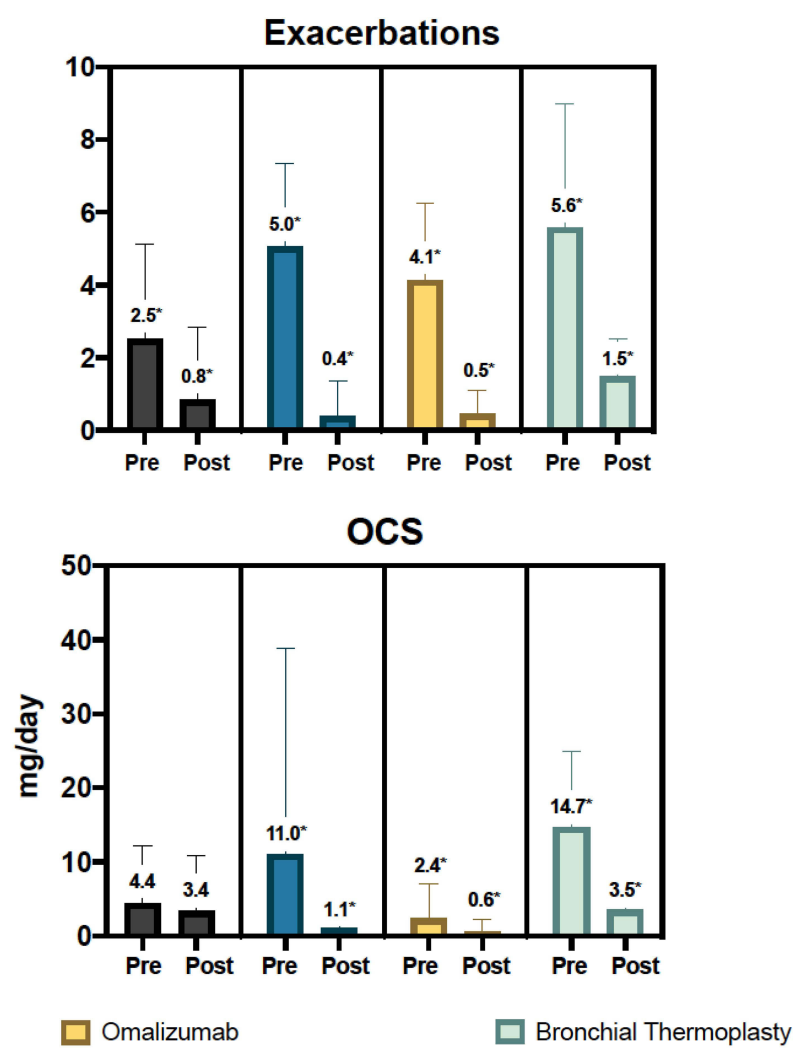

Figure I Comparison of changes in primary outcomes. Note: The * indicates a statistically significant difference between the groups.

observation period, a high OCS sparing effect was confirmed with almost complete weaning from OCS (mean residual dose $1.1 \mathrm{mg}$ ). The improvement in $\mathrm{FEV}_{1}, \mathrm{ACT}$, ACQ and AQLQ scores was significant, although the improvement in respiratory function was superior with benralizumab, as shown by previous findings. ${ }^{15,16}$ This drug is the one that obtained the best results in terms of reduction of hospitalizations and exacerbations as well. Furthermore, patients in the benralizumab group were those with the greatest respiratory impairment at baseline $\left(\mathrm{FEV}_{1} 60.5 \%\right)$, an aspect that made the improvement in $\mathrm{FEV}_{1}$ even more important than just the numerical increase. Moreover, we obtained a significant steroid-sparing effect with benralizumab (although lower than mepolizumab) and improvements in ACT and ACQ, but not in AQLQ. These data, together with the lower baseline OCS dose $(4.4 \mathrm{mg})$ compared to the mepolizumab-treated subgroup could suggest a greater stability of asthma in benralizumabtreated patients, confirmed by the lowest number of pretreatment exacerbations (2.4) compared to the other subgroups. Regarding omalizumab treated population, the improvements in $\mathrm{FEV}_{1}, \mathrm{ACT}$, ACQ and AQLQ were significant, confirming the effectiveness of this proven and always effective drug. The lower baseline OCS dose $(2.4 \mathrm{mg})$ compared to the one in patients treated with mepolizumab and benralizumab should be highlighted, as it is compatible with the phenotype of patients eligible for omalizumab ("early onset" allergic asthma with fewer comorbidities). It is relevant that subjects enrolled in this subgroup achieved almost complete OCS-weaning, considering that for omalizumab the OCS sparing effect data are less robust than other biologics; no randomized clinical trials (RCTs) based on this important outcome have been conducted, although some open-label and real-life studies indicated the positive effect of omalizumab on the reduction of OCS and consequently the impact on the reduction of the OCSrelated complications. ${ }^{17,18}$ It is necessary to point out that the greater percentage $(65 \%)$ of atopic patients in the enrolled population compared to those subsequently treated with omalizumab (27\%) was due to the fact that 
Table 3 Outcomes Variations in Omalizumab Group

\begin{tabular}{|c|c|c|c|}
\hline \multicolumn{4}{|c|}{ Omalizumab } \\
\hline & Pre & Post & p value \\
\hline Eos $($ cell $/ \mathrm{mcl})$, mean $\pm \mathrm{SD}$ & $325.8 \pm 331.2$ & $331.8 \pm 293.5$ & 0.86 \\
\hline Eos (\%), mean \pm SD & $4.2 \pm 3.6$ & $4.4 \pm 3.5$ & 0.94 \\
\hline Neutr $($ cell $/ \mathrm{mcl})$, mean \pm SD & $4760 \pm 2189$ & $4498 \pm 1478$ & 0.76 \\
\hline Neutr (\%), mean \pm SD & $58.1 \pm 12.6$ & $56.6 \pm 7.8$ & 0.69 \\
\hline $\lg \mathrm{E}$ tot $(\mathrm{kU} / \mathrm{L})$, mean $\pm \mathrm{SD}$ & $586.8 \pm 910.3$ & $578 \pm 621$ & 0.91 \\
\hline $\mathrm{ACT}$, mean $\pm \mathrm{SD}$ & $14.7 \pm 3.7$ & $21.9 \pm 2$ & $<0.0001$ \\
\hline $\mathrm{ACQ}$, mean $\pm \mathrm{SD}$ & $3 \pm 0.7$ & $1.8 \pm 0.7$ & $<0.0001$ \\
\hline AQLQ, mean \pm SD & $4.8 \pm 0.9$ & $5.5 \pm 0.8$ & 0.0003 \\
\hline Hospitalizations in the last year, mean \pm SD & $0.3 \pm 0.6$ & $0.04 \pm 0.2$ & 0.012 \\
\hline Exacerbations in the last year, mean $\pm S D$ & $4.1 \pm 2.1$ & $0.5 \pm 0.6$ & $<0.0001$ \\
\hline $\mathrm{FEV}_{\mathrm{I}}(\mathrm{L})$, mean $\pm \mathrm{SD}$ & $1.9 \pm 0.8$ & $2.2 \pm 1$ & 0.0006 \\
\hline $\mathrm{FEV}_{\text {। }}(\%)$, mean $\pm \mathrm{SD}$ & $65.3 \pm 13.3$ & $73.7 \pm 16.5$ & $<0.0001$ \\
\hline $\mathrm{FVC}(\mathrm{L})$, mean $\pm \mathrm{SD}$ & $3 \pm 1.1$ & $3.2 \pm 1.3$ & 0.15 \\
\hline $\mathrm{FVC}(\%)$, mean $\pm \mathrm{SD}$ & $82.8 \pm 15.9$ & $85.8 \pm 17.3$ & 0.09 \\
\hline $\mathrm{FEV}_{1} / \mathrm{FVC}$, mean $\pm \mathrm{SD}$ & $69.1 \pm 12.3$ & $69.3 \pm 10.6$ & 0.35 \\
\hline ICS (mcg/die), mean \pm SD & $798.8 \pm 237$ & $873.7 \pm 345.6$ & 0.21 \\
\hline OCS $(\mathrm{mg} / \mathrm{die})$, mean $\pm \mathrm{SD}$ & $2.4 \pm 4.7$ & $0.6 \pm 1.7$ & 0.006 \\
\hline LAMA, n (\%) & $27(50)$ & $23(42.6)$ & 0.56 \\
\hline LTRA, n (\%) & $33(6 I)$ & $29(53.7)$ & 0.56 \\
\hline Theophylline, n (\%) & $5(9.3)$ & $0(0)$ & 0.056 \\
\hline
\end{tabular}

a part of these subjects were not eligible for anti-IgE due to elevated IgE values and/or excessive body weight.

Regarding exacerbations rate, all 3 monoclonal antibodies (mAbs) allowed a significant reduction, although the best results were obtained in patients treated with mepolizumab and omalizumab (who also had a higher number of exacerbations at baseline). This latest $\mathrm{mAb}$ is the one that has obtained the highest percentage of super responder patients, confirming its reliability despite being the first biologic introduced for the treatment of SRA. However, this finding may have been influenced at least partially by the smaller number of patients in the benralizumab group.

The results on BT were positive and reassuring about the efficacy of this non-drug treatment. We previously mentioned how this non-pharmacological option is often reserved for patients who are not eligible or nonresponders to biologics or with T2-"low" asthma. Therefore, BT can be seen as a last resort option, also due to the lack of general consensus on identifying the ideal patient. Compared to biological drugs, no changes in biomarkers, in particular $\mathrm{BEC}$ and $\mathrm{IgE}$, were observed. Respiratory function also did not improve, so BT appeared worse than biologics. However, interesting data emerged about significant reduction in hospitalizations and exacerbations that were comparable to the result of mepolizumab and omalizumab, whilst superior to benralizumab. The OCS-sparing effect was also significant, even more important as it was achieved in a subpopulation with a higher baseline prednisone 
Table 4 Outcomes Variations in Mepolizumab Group

\begin{tabular}{|c|c|c|c|}
\hline \multicolumn{4}{|c|}{ Mepolizumab } \\
\hline & Pre & Post & p value \\
\hline Eos $($ cell $/ \mathrm{mcl})$, mean $\pm S D$ & $511.7 \pm 238.5$ & $139.2 \pm 389.9$ & $<0.0001$ \\
\hline Eos $(\%)$, mean $\pm S D$ & $6.9 \pm 3.3$ & $1.5 \pm 2.2$ & $<0.0001$ \\
\hline Neutr (cell/mcl), mean $\pm S D$ & $4498 \pm 1684$ & $5381 \pm 1323$ & 0.0004 \\
\hline Neutr (\%), mean \pm SD & $54.6 \pm 11.3$ & $59.7 \pm 7.5$ & 0.003 \\
\hline $\operatorname{lgE}$ tot $(\mathrm{kU} / \mathrm{L})$, mean $\pm \mathrm{SD}$ & $336.3 \pm 529$ & $229.2 \pm 504.8$ & $<0.0001$ \\
\hline $\mathrm{ACT}$, mean $\pm \mathrm{SD}$ & $15.3 \pm 4.2$ & $22.7 \pm 2.5$ & $<0.0001$ \\
\hline$A C Q$, mean $\pm S D$ & $3.6 \pm 0.6$ & $2.3 \pm 0.9$ & $<0.0001$ \\
\hline $\mathrm{AQLQ}$, mean $\pm \mathrm{SD}$ & $3.9 \pm 1.1$ & $5.1 \pm 1$ & 0.001 \\
\hline Hospitalizations in the last year, mean $\pm S D$ & $0.3 \pm 0.9$ & $0.03 \pm 0.2$ & 0.02 \\
\hline Exacerbations in the last year, mean $\pm S D$ & $5 \pm 2.3$ & $0.4 \pm 0.9$ & $<0.0001$ \\
\hline $\mathrm{FEV}_{\mathrm{I}}(\mathrm{L})$, mean $\pm \mathrm{SD}$ & $1.9 \pm 0.8$ & $2.2 \pm 0.8$ & $<0.0001$ \\
\hline $\mathrm{FEV}_{1}(\%)$, mean $\pm \mathrm{SD}$ & $70.9 \pm 19.7$ & $82.3 \pm 15.9$ & $<0.0001$ \\
\hline $\mathrm{FVC}(\mathrm{L})$, mean $\pm \mathrm{SD}$ & $2.7 \pm 1$ & $3 \pm 1.1$ & $<0.0001$ \\
\hline FVC (\%), mean \pm SD & $83.6 \pm 16.2$ & $93.2 \pm 14.6$ & $<0.0001$ \\
\hline $\mathrm{FEV}_{\mathrm{l}} / \mathrm{FVC}$, mean $\pm \mathrm{SD}$ & $68.2 \pm 11$ & $72.4 \pm 8.9$ & 0.002 \\
\hline ICS (mcg/die), mean \pm SD & $1086 \pm 413.4$ & $1072 \pm 425.6$ & 0.79 \\
\hline OCS (mg/die), mean \pm SD & $11 \pm 27.8$ & $1.1 \pm 4.6$ & 0.002 \\
\hline LAMA, n (\%) & $70(84.3)$ & $55(63.3)$ & 0.01 \\
\hline LTRA, n (\%) & $34(4 I)$ & $22(26.5)$ & 0.07 \\
\hline Theophylline, n (\%) & $6(7.2)$ & $0(0)$ & 0.03 \\
\hline
\end{tabular}

dose (14.6 mg) compared to the sub-population treated with mAbs. ACT, ACQ and AQLQ scores also improved significantly, supporting BT effectiveness on improving asthma control and QoL. In the RISA RCT, OCS use decreased by $63.5 \%$ in BT-treated patients, compared with $26.2 \%$ and $20 \%$ in the control group. Significant improvements in QoL and asthma symptom scores were observed up to 4 months after the steroid weaning phase. ${ }^{19}$ A real-life study on a small population confirmed the clinical efficacy of BT but even showed an increased need for rescue courses of OCS. ${ }^{20}$

As for therapeutic switches, these were infrequent and occurred mainly between omalizumab and BT sub-groups. Twenty percent of patients were switched between omalizumab and BT. This was due to non-response to anti$\operatorname{IgE}$ or clinical worsening during the course of treatment and they were ineligible for other biologics. It is important to note that the clinical benefits and the OCS-sparing effect after BT also allowed this subgroup of patients to obtain an improvement in asthma control and to avoid important OCS side effects.

As limitations of this paper, we must recognize that this is a retrospective observational study and not an RCT. A control arm is not available and a selection bias in the choice of treatments may be present. However, there are currently no other published data that compare results of different $\mathrm{mAbs}$ with $\mathrm{BT}$ and there are no RCT in progress. ${ }^{21}$ Probably, the major limitation of this study is 
Table 5 Outcomes Variations in Bronchial Thermoplasty Group

\begin{tabular}{|c|c|c|c|}
\hline & \multicolumn{3}{|c|}{ Bronchial Thermoplasty } \\
\hline & Pre & Post & p value \\
\hline Eos $($ cell $/ \mathrm{mcl})$, mean $\pm S D$ & $365 \pm 552.8$ & $392 \pm 284.3$ & 0.77 \\
\hline Eos $(\%)$, mean \pm SD & $3.8 \pm 5.6$ & $4.9 \pm 3.4$ & 0.28 \\
\hline Neutr $($ cell $/ \mathrm{mcl})$, mean \pm SD & $4557 \pm 2058$ & $4363 \pm 1679$ & 0.41 \\
\hline Neutr (\%), mean \pm SD & $51.8 \pm 14.5$ & $50.1 \pm 11.7$ & 0.47 \\
\hline $\lg \mathrm{E}$ tot $(\mathrm{kU} / \mathrm{L})$, mean $\pm \mathrm{SD}$ & $137.1 \pm 152.3$ & $166.5 \pm 192.9$ & 0.54 \\
\hline $\mathrm{ACT}$, mean $\pm \mathrm{SD}$ & $13.9 \pm 3.8$ & $19.9 \pm 4.4$ & $<0.0001$ \\
\hline $\mathrm{ACQ}$, mean $\pm \mathrm{SD}$ & $3.2 \pm 0.9$ & $2.1 \pm 0.9$ & $<0.0001$ \\
\hline AQLQ, mean \pm SD & $3.6 \pm 1.1$ & $4.8 \pm 1.2$ & 0.0004 \\
\hline Hospitalizations in the last year, mean \pm SD & $1.1 \pm 1.6$ & $0.07 \pm 0.2$ & 0.001 \\
\hline Exacerbations in the last year, mean $\pm S D$ & $5.6 \pm 3.4$ & $1.5 \pm 1$ & $<0.0001$ \\
\hline $\mathrm{FEV}_{\mathrm{I}}(\mathrm{L})$, mean $\pm \mathrm{SD}$ & $2 \pm 0.7$ & $2.2 \pm 0.8$ & 0.29 \\
\hline $\mathrm{FEV}_{\text {। }}(\%)$, mean $\pm \mathrm{SD}$ & $71.2 \pm 19.6$ & $70.6 \pm 21.2$ & 0.77 \\
\hline $\mathrm{FVC}(\mathrm{L})$, mean $\pm \mathrm{SD}$ & $3.3 \pm 0.9$ & $3.2 \pm 1$ & 0.18 \\
\hline $\mathrm{FVC}(\%)$, mean $\pm \mathrm{SD}$ & $92.3 \pm 17.3$ & $84 \pm 18.5$ & 0.004 \\
\hline $\mathrm{FEV}_{1} / \mathrm{FVC}$, mean $\pm \mathrm{SD}$ & $65.8 \pm 15$ & $69.2 \pm 12.9$ & 0.13 \\
\hline ICS $(\mathrm{mcg} / \mathrm{die})$, mean $\pm \mathrm{SD}$ & $1255 \pm 592$ & $1393 \pm 595.7$ & 0.26 \\
\hline OCS (mg/die), mean \pm SD & $14.7 \pm 10.2$ & $3.5 \pm 4.9$ & $<0.0001$ \\
\hline LAMA, n (\%) & $17(56.7)$ & $23(76.7)$ & 0.17 \\
\hline LTRA, n (\%) & II (36.7) & $5(16.7)$ & 0.14 \\
\hline Theophylline, n (\%) & $5(16.7)$ & I (3.3) & 0.19 \\
\hline
\end{tabular}

the difference in the number of patients included in the various treatment groups, which may have led to bias in patient inclusion. However, such differences may be acceptable in a real-life retrospective study.

Concordance in results of the different treatments is the most innovative and interesting aspect of this study and it provides important information on outcomes of different therapeutic options in patients with SRA and different phenotypes treated in a real-world setting.

\section{Abbreviations}

SRA, severe refractory asthma; mAbs, monoclonal antibodies; IL-5, interleukin-5; (T2)-high, Type 2 high; BT, bronchial thermoplasty; FDA, US Food and Drug Administration; ED, emergency department; AQLQ, asthma quality of life questionnaire; ACQ, asthma control questionnaire; ICS/LABA, inhaled corticosteroids/longacting $\beta$-adrenoceptor agonists; LAMA, long-acting muscarinic antagonists; LTRA, leukotriene receptor antagonists; OCS, oral corticosteroids (OCS); $\mathrm{FEV}_{1}$, forced expiratory volume; QoL, quality of life; BEC, blood eosinophil count.

\section{Data Sharing Statement}

The data presented in this study are available on request from the corresponding author.

\section{Ethics Approval}

This study was approved by the local ethics committee (Ethics Committee of the Vast Emilia North Area Azienda USL di Reggio Emilia- IRCCS, Reggio Emilia 15/11/2017), protocol number 2020/0013491 and Ethics 

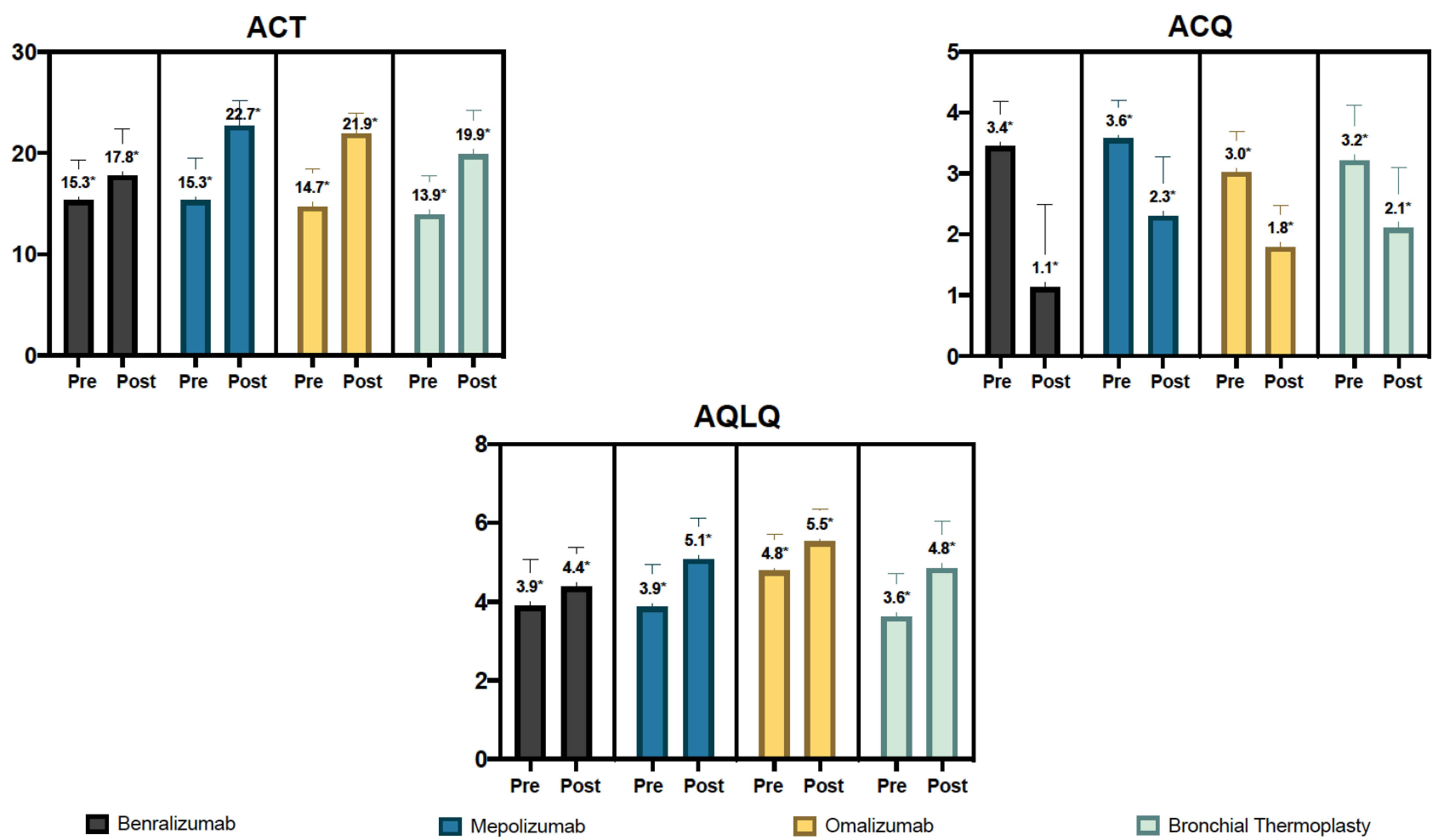

Benralizumab

$\square$ Mepolizumab

Omalizumab

Bronchial Thermoplasty

Figure 2 Comparison of changes in ACT, ACQ and AQLQ scores. The * indicates a statistically significant difference between the groups. The range markers stand for the standard deviation.

Committee of University "Luigi Vanvitelli" - AORN “Ospedali dei Colli” protocol number 11652/2020.

\section{Consent for Publication}

Informed consent was obtained from all subjects involved in the study.

\section{Author Contributions}

All authors made a significant contribution to the work reported, whether that is in the conception, study design, execution, acquisition of data, analysis and interpretation, or in all these areas. All authors took part in drafting, revising or critically reviewing the article; they gave final approval of the version to be published, they agreed on the journal to which the article has been submitted and they agreed to be accountable for all aspects of the work.

\section{Funding}

There is no funding to report.

\section{Disclosure}

The authors declare that they have no competing interests.

\section{References}

1. Bagnasco D, Passalacqua G, Caminati M, et al. Evolving phenotypes to endotypes: is precision medicine achievable in asthma? Expert Rev Respir Med. 2020;14(2):163-172. doi:10.1080/17476348.2 020.1703675

2. Fahy JV. Type 2 inflammation in asthma - present in most, absent in many. Nat Rev Immunol. 2015;15(1):57-65. doi:10.1038/nri3786

3. Menzella F, Ruggiero P, Ghidoni G, et al. Anti-IL5 therapies for severe eosinophilic asthma: literature review and practical insights. $J$ Asthma Allergy. 2020;13:301-313. doi:10.2147/JAA.S258594

4. Menzella F, Lusuardi M, Galeone C, et al. Bronchial thermoplasty and the role of airway smooth muscle: are we on the right direction? Ther Clin Risk Manag. 2017;13:1213-1221. doi:10.2147/TCRM. S144604

5. Thomson NC. Recent developments in bronchial thermoplasty for severe asthma. J Asthma Allergy. 2019;12:375-387. doi:10.2147/ JAA.S200912

6. Holguin F, Cardet JC, Chung KF, et al. Management of severe asthma: a European Respiratory Society/American Thoracic Society guideline. Eur Respir J. 2020;55(1):1900588. doi:10.1183/ 13993003.00588-2019

7. Available from: https://ginasthma.org/wp-content/uploads/2020/06/ GINA-2020-report_20_06_04-1-wms.pdf. Accessed May 27, 2021.

8. Bourdin A, Husereau D, Molinari N, et al. Matching-adjusted indirect comparison of benralizumab versus interleukin-5 inhibitors for the treatment of severe asthma: a systematic review. Eur Respir J. 2018;52(5):1801393. doi:10.1183/13993003.01393-2018

9. Busse W, Chupp G, Nagase H, et al. Anti-IL-5 treatments in patients with severe asthma by blood eosinophil thresholds: indirect treatment comparison. J Allergy Clin Immunol. 2019;143(1):190-200.e20. doi:10.1016/j.jaci.2018.08.031 
10. Menzella F, Latorre M, Ruggiero P, Bagnasco D, Heffler E Reduction of oral corticosteroids in patients with severe eosinophilic asthma treated with Benralizumab: could it represent a marker of treatment efficacy? Expert Opin Biol Ther. 2019;19(7):601-606. doi:10.1080/14712598.2019.1613367

11. Langton D, Sha J, Guo S, et al. Bronchial thermoplasty versus mepolizumab: comparison of outcomes in a severe asthma clinic. Respirology. 2020;25(12):1243-1249. doi:10.1111/resp.13830

12. Castro M, Rubin AS, Laviolette M, et al. Effectiveness and safety of bronchial thermoplasty in the treatment of severe asthma: a multicenter, randomized, double-blind, sham-controlled clinical trial. Am J Respir Crit Care Med. 2010;181(2):116-124. doi:10.1164/rccm.200903-0354OC

13. Langton D, Ing A, Fielding D, et al. Safety and effectiveness of bronchial thermoplasty when FEV1 is less than 50. Chest. 2020;157 (3):509-515. doi:10.1016/j.chest.2019.08.2193

14. Menzella F, Galeone C, Ruggiero P, Bagnasco D, Catellani C, Facciolongo N. Biologics and bronchial thermoplasty for severe refractory asthma treatment: from eligibility criteria to real practice. A cross-sectional study. Pulm Pharmacol Ther. 2020;60:101874. doi:10.1016/j.pupt.2019.101874

15. Pelaia C, Busceti MT, Crimi C, et al. Real-Life effects of benralizumab on exacerbation number and lung hyperinflation in atopic patients with severe eosinophilic asthma. Biomed Pharmacother. 2020;129:110444. doi:10.1016/j.biopha.2020.110444
16. Menzella F, Ruggiero P, Galeone C, Scelfo C, Bagnasco D, Facciolongo N. Significant improvement in lung function and asthma control after benralizumab treatment for severe refractory eosinophilic asthma. Pulm Pharmacol Ther. 2020;64:101966. doi:10.1016/j. pupt.2020.101966

17. Siergiejko Z, Świebocka E, Smith N, et al. Oral corticosteroid sparing with omalizumab in severe allergic (IgE-mediated) asthma patients. Curr Med Res Opin. 2011;27(11):2223-2228. doi:10.1185/ 03007995.2011.620950

18. Molimard M, Buhl R, Niven R, et al. Omalizumab reduces oral corticosteroid use in patients with severe allergic asthma: real-life data. Respir Med. 2010;104(9):1381-1385. doi:10.1016/j. rmed.2010.06.001

19. Pavord ID, Cox G, Thomson NC, et al. Safety and efficacy of bronchial thermoplasty in symptomatic, severe asthma. Am J Respir Crit Care Med. 2007;176:1185-1191. doi:10.1164/rccm.200704-571OC

20. Madsen H, Henriksen DP, Backer V, Siersted HC, Bjerring N, Ulrik CS. Efficacy of bronchial thermoplasty in patients with severe asthma. J Asthma. 2019:1-7. doi:10.1080/02770903.2019.1678636

21. NIH. U.S National Library of Medicine. Available from: http://clin icaltrials.gov. Accessed May 2, 2021.

\section{Publish your work in this journal}

The Journal of Asthma and Allergy is an international, peer-reviewed open-access journal publishing original research, reports, editorials and commentaries on the following topics: Asthma; Pulmonary physiology; Asthma related clinical health; Clinical immunology and the immunological basis of disease; Pharmacological interventions and new therapies. The manuscript management system is completely online and includes a very quick and fair peer-review system, which is all easy to use. Visit http://www.dovepress.com/testimonials.php to read real quotes from published authors. 